\title{
Socioeconomic status, financial hardship and measured obesity in older adults: a cross-sectional study of the EPIC-Norfolk cohort
}

Annalijn I Conklin ${ }^{1,2}$, Nita G Forouhi ${ }^{1}$, Marc Suhrcke ${ }^{2,3}$, Paul Surtees ${ }^{4}$, Nicholas J Wareham ${ }^{1,2}$ and Pablo Monsivais ${ }^{2,4^{*}}$

\begin{abstract}
Background: Socioeconomic status is strongly associated with obesity. Current economic circumstances are also independently associated with self-reported weight status in Finnish civil servants. We aimed to examine three types of financial hardship in relation to measured general and central obesity in a general population of older adults, while considering conventional socioeconomic indicators.
\end{abstract}

Methods: Data from 10,137 participants ( $\geq 50$ years) in the EPIC-Norfolk cohort who responded to a postal Health and Life Experiences Questionnaire (1996-2000) and attended a clinical assessment (1998-2002). Multivariable logistic regression models assessed likelihood of general obesity $\left(\mathrm{BMI} \geq 30 \mathrm{~kg} / \mathrm{m}^{2}\right.$ ) and central obesity (women: $\geq 88 \mathrm{~cm}$; men: $\geq 102 \mathrm{~cm}$ ) calculated from measured anthropometrics.

Results: Obesity prevalence was consistently patterned by standard socioeconomic indicators, with over-50s in the lowest social class being twice as likely to be obese than those in the highest class (women OR 2.10 [Cl95: 1.41-3.13]; men OR 2.36 [1.44-3.87]). After adjustment for socioeconomic status, reporting having less than enough money for one's needs (compared to more than enough) was associated with obesity in women (OR 2.04 [1.54-2.69]) and men (OR 1.83 [1.34-2.49]). Similar associations were demonstrated between obesity and always or often not having enough money for food/clothing (women OR 1.40 [1.03-1.90]; men OR 1.81 [1.28-2.56]), compared to reporting this never occurred. The strongest independent associations were seen for obesity and reported greatest level of difficulty paying bills (women OR 2.20 [1.37-3.55]; men 2.40 [1.38-4.17]), compared to having no difficulties. Findings for central obesity were slightly higher in women and lower in men.

Conclusions: Obesity in British over-50s was more likely in study participants who reported greater financial hardship, even after education, social class and home ownership were taken into account. Public health policies need to consider the hitherto neglected role of financial hardship in older people, especially difficulty paying bills, as part of strategies to prevent or reduce obesity.

Keywords: Body mass index, Waist circumference, Anthropometry, Socioeconomic status, Financial hardship, Elderly, Healthy ageing, EPIC-Norfolk

\footnotetext{
* Correspondence: pm491@medschl.cam.ac.uk

${ }^{2} U K$ Clinical Research Collaboration Centre for Diet and Activity Research (CEDAR), Institute of Public Health, Forvie Site, Robinson Way, Box 296, Cambridge CB2 OSR, UK

${ }^{4}$ Department of Public Health and Primary Care, Institute of Public Health, University of Cambridge, Cambridge CB1 8RN, UK

Full list of author information is available at the end of the article
} 


\section{Background}

Obesity is one of the biggest public health challenges faced by high income countries, accounting for a large and growing disease burden (cardiovascular disease, type 2 diabetes, some cancers) and imposing substantial cost burden on both the healthcare system and society at large [1-3]. Both general (weight status) and central (excess abdominal fat) obesity significantly increase a person's risk of, for example, cardiometabolic conditions [4]. Obesity is strongly and inversely related to socioeconomic status (SES) as measured by conventional indicators of education or social class, particularly in the case of women [5-7]. But, conventional SES has been acknowledged as insufficient to understand how a person's economic situation is associated with their body mass index (BMI) or waist circumference (WC) [8], and differences in obesity by education or income are not consistently observed in UK adults [9].

A limitation with conventional SES indicators is that they do not fully capture people's material circumstances and spending power, whereas everyday financial troubles may be a stronger antecedent to obesity than income, occupational status, or education [8,10]. Wider research on poverty has highlighted the added value of material hardship measures to concepts of inequality [11]. Evidence from two occupational cohorts supports the notion that financial hardship reflects a distinct set of economic factors that independently impacts health beyond the reported influence exerted by conventional SES [8,10,12-15]. Another study found an association between financial hardship and smoking even within high-income groups [16]. To date, one longitudinal study of US adolescents explored separate types of financial hardship and found suggestive evidence that having trouble paying bills may be related to obesity in women, but not men [17].

Financial hardship is closely correlated, but not interchangeable, with conventional SES and therefore deserves specific attention [18]. Since individuals at all income levels can experience financial hardship with consequent health effects, the implications for public health and policy are that income (or other standard SES indicators) should not be seen as the sole criteria for targeting interventions [12,18-20]. One of the largest drains on disposable income, especially in older people, is paying bills and affording adequate food and clothing [21], and yet, health research and policy has tended to neglect current financial difficulties as a unique economic domain determining health. Consequently, evidence remains limited on the role of financial hardship in obesity and whether separate types of hardship differ in their associations with obesity, particularly among older adults who comprise a growing population $[8,19,22]$. Older adults with greater hardships may purchase less food and have lower weights due to fewer calories; however, they may also purchase cheaper food high in energy density which could contribute to excess weight.

We therefore investigated the sex-specific associations between three types of self-reported financial hardships and obesity measured objectively in adults aged 50 and older. We hypothesised that greater levels of financial hardship may be associated with greater odds of obesity, overall and centrally, with sex differences in magnitude of associations. We further hypothesised that associations would remain significant after adjusting for conventional socioeconomic status.

\section{Methods}

\section{Study population}

We used data collected as part of the EPIC-Norfolk prospective cohort study-a component of the European Prospective Investigation of Cancer (EPIC) study in 10 European countries [23]. As we were interested in adults near the end of working life and beyond to place findings in a healthy ageing context, we included over-50s ( $\mathrm{n}=$ 20,274 ) from the population-based cohort who were recruited from age-sex registers of general practices and who attended a first health check at entry (199397). At entry, over-50s were similar to the total cohort $(\mathrm{n}=25,639)$ in terms of health behaviours and other socio-demographic factors. Ethnicity of $99.7 \%$ of EPICNorfolk participants was of white origin.

Financial hardship was assessed using the postal "Health and Life Experiences Questionnaire" (HLEQ) (1996-2000) designed to assess social and psychological circumstances $[24,25]$. Completed responses from over50s ranged between 17,953 and 17,998. Outcome data on BMI $(\mathrm{n}=11,982)$ and WC $(\mathrm{n}=12,000)$ were measured objectively during a second clinical assessment (19982002). Our available sample therefore included over-50s who responded to financial hardship questions, had covariates and follow-up anthropometry (range: 10,11310,137) with $99 \%$ complete data (see Additional file 1: Figure S1). The sample was similar in characteristics and lifestyle to responders in the full cohort, and over-50s not responding to hardship questions were similar to cohort non-responders. All volunteers gave written informed consent and the study was approved by the Norwich district ethics committee.

\section{Measures}

Financial hardship and conventional socioeconomic indicators Financial hardship was measured by three self-reported questions in line with Pearlin's list of chronic strains as used in similar studies $[12,20]$. Questions covered sufficiency of money to meet needs (more than enough, just enough, less than enough), frequency of not having enough money to afford adequate food or clothing (5 responses, range 'always' to 'never'), and difficulty paying 
bills (6 responses, range 'very great' to 'none'). Responses 'always' and 'often', or 'great' and 'very great', were combined for analysis due to low numbers in the bottom two categories.

We analysed three conventional indicators of SES. Education level (no qualification, O-level (16 years), Alevel (18 years), degree (>18 years)) and occupation were self-reported at cohort entry, with occupation used to classify participants into six hierarchical categories of the Registrar General's classification scheme of social class (professional, managerial and technical, skilled non-manual, skilled manual, partly skilled, and unskilled). Social class in women was based on her partner's occupation (68\%) unless it was unclassified, missing, or they were single and then her own occupation was used [26]. We also employed a measure of housing tenure (home-owner, public renting, private renting) as a conventional SES proxy, given that previous research has documented the utility of home ownership as a measure of wealth in older populations [27].

\section{Obesity}

Trained nurses used standardised protocols to measure weight, height, and WC of all participants attending the second clinic assessment, as reported elsewhere [26,28]. BMI was calculated as weight in kilograms divided by the square of height in metres. Participants who had a $\mathrm{BMI} \geq 30 \mathrm{~kg} / \mathrm{m}^{2}$ were classified as obese overall. Central obesity was calculated using sex-specific threshold criteria for WC: women with $\mathrm{WC} \geq 88 \mathrm{~cm}$ and men with $\mathrm{WC} \geq$ $102 \mathrm{~cm}$ were classified as centrally obese.

\section{Socio-demographic variables}

Participants self-reported smoking status (current, former, never), marital status (married/living as married, single, widowed, separate, divorced), and general health status (excellent, good, moderate, poor), at second health check (1998-2002). Regular car use (yes/no) was self-reported in the Environment and Physical Activity questionnaire (EPAQ2) (1998-2000). Socio-demographic variables for date of birth (continuous age) and sex were measured at cohort entry.

\section{Data analysis}

Descriptive statistics summarised socio-demographic characteristics (sex, education, social class, home-ownership, car use, health status, smoking status, marital status), and crude prevalence of obesity across financial hardship levels. We used a correlation matrix to examine interrelationships among the financial hardship indicators after recoding two indicators into three levels: frequency of not having enough money for food or clothing (never; sometimes/seldom; often/always), and difficulty paying bills (none; very little/slight; some/great/very great). Odds ratios of prevalent obesity for the six socioeconomic indicators were examined by fitting logistic regression models a priori sex-stratified and adjusted for age, smoking status and marital status. As known confounders, each is associated with socioeconomic factors and independently with obesity [29-32].

For each categorical measure of financial hardship, we fitted sequential logistic regression models to base models (sex-stratified and adjusted for age, smoking and marital status); first by education, followed by occupational social class, and then housing tenure. The final model for each hardship indicator mutually adjusted for all conventional SES and covariates and therefore the remaining sexspecific odds ratios for general and central obesity were interpreted as independent associations of the financial hardship variable in question.

In secondary analyses, we further adjusted for concurrent lifestyle variables: total energy intake (Kcal), total alcohol consumption (units/week), and physical activity and energy expenditure (PAEE) score. Self-reported total energy and alcohol intake were assessed by food frequency questionnaire [33]; and PAEE by the EPAQ2 questionnaire, previously validated against individually calibrated heart rate against energy expenditure [34]. For women, we also adjusted for menopause and HRT status in secondary models.

Statistical analyses were performed separately for women and men using Stata 12.1 [35]. Results are presented as odds ratios (ORs) and 95 percent confidence intervals (95\% CIs).

\section{Results}

The mean age of participants was 62.5 years (SD 7.5) with $54 \%$ of the sample made up of women. A majority (81\%) reported being in good or excellent general health, and $51 \%$ were ever smokers. For the whole sample, 11\% were educated to degree-level; $14 \%$ of men and $9 \%$ of women were educated to this level. Professional (class I), and managerial and technical (class II), occupations comprised $42 \%$ of the sample; few women (4\%) and men (3\%) had unskilled occupations. Mean BMI was $27 \mathrm{~kg} /$ $\mathrm{m}^{2}$ (SD 3.3) in men, and $26.8 \mathrm{~kg} / \mathrm{m}^{2}$ (SD 4.4) in women; $16 \%$ of men and $20 \%$ of women were classified as obese overall. Women's average WC was $82.9 \mathrm{~cm}$ (SD 10.6) and men's was $96.7 \mathrm{~cm}$ (SD 9.6); 29\% of women and $27 \%$ of men were classified as being centrally obese.

There was a close inter-relationship between the three measures of self-reported financial hardship and other socio-demographic measures (see Additional file 1: Table $\mathrm{S} 2$ ). We found that the three financial hardship measures were moderately related to each other. The indicator having enough money for needs shared 23\% and 26\% of its variability with the indicators frequency of not having enough money for food or clothing $(r=0.48)$ and 
difficulty paying bills $(\mathrm{r}=0.51)$, respectively. Frequency of not having enough money for food or clothing shared $38 \%$ of its variability with difficulty paying bills $(\mathrm{r}=0.62)$.

\section{Conventional SES indicators and odds of obesity}

There was a clear pattern of association between lower levels of social class, education, and housing tenure and general and central obesity in sex-specific models adjusted for covariates (Table 1). The lowest social class (V) was significantly associated with greater odds of general obesity in women (OR 2.10; 1.41-3.13) and men (OR $2.36 ; 1.44-3.87)$ aged 50 and over. Similar sex-specific associations were observed between social class and central obesity, but reached significance only in women. Women and men who reported having no educational qualification were more likely to be obese centrally and overall, although odds ratios were larger in men for both outcomes. Similarly, obesity was more likely in women and men who reported renting public or private accommodation (compared with owning); magnitudes were largest for general obesity in men who rented accommodation.

Further adjustment for total energy intake, physical activity and alcohol intake attenuated or made little difference to most of the associations between conventional SES indicators and obesity (see Additional file 1: Table S3). Addition of menopause and HRT status made no difference to overall magnitude or direction of findings for women (data not shown).

\section{Financial hardship and odds of obesity}

In an analysis adjusting for age, smoking status, and marital status, all three measures of financial hardship were strongly associated with obesity in both sexes (Model A, Table 2). The magnitude of association was greater than that seen for the more traditional measures of SES. In general the measures of association were similar in men and women.

A somewhat different pattern was observed for associations with central obesity which tended to be stronger in women than men (Model A, Table 3). Adjusting for education, social class, and housing tenure attenuated the associations between financial hardship and odds of general and central obesity (Model D, Table 2 and Table 3).

Additional adjustment for other lifestyle variables had little effect on the measures of association either for general or central obesity (see Additional file 1: Table S4 and Table S5).

\section{Discussion}

\section{Synopsis of results}

This cross-sectional, population-based study of UK over50s showed social class, education, and housing tenure gradients in obesity. It further demonstrated strong

Table 1 Odds ratios of general and central obesity in women and men ( $\geq 50$ years) across levels of social class, education, and housing tenure in the EPIC-Norfolk cohort

\begin{tabular}{|c|c|c|c|c|}
\hline & & & & \\
\hline & Women & Men & Women & Men \\
\hline Social Class & $(n=6320)$ & $(n=5277)$ & $(n=6327)$ & $(n=5286)$ \\
\hline I & 1.00 & 1.00 & 1.00 & 1.00 \\
\hline$\|$ & $1.29(0.96,1.72)$ & $1.33(0.96,1.84)$ & $1.11(0.88,1.41)$ & $1.08(0.85,1.37)$ \\
\hline III-non manual & $1.23(0.90,1.66)$ & $1.57(1.09,2.26)$ & $0.99(0.77,1.28)$ & $1.13(0.86,1.49)$ \\
\hline III-manual & $1.49(1.10,2.02)$ & $1.53(1.09,2.14)$ & $1.10(0.85,1.41)$ & $1.03(0.80,1.34)$ \\
\hline IV & $2.10(1.53,2.86)$ & $1.36(0.94,1.96)$ & $1.41(1.08,1.84)$ & $1.10(0.83,1.45)$ \\
\hline V & $2.10(1.41,3.13)$ & $2.36(1.44,3.87)$ & $1.57(1.11,2.22)$ & $1.47(0.97,2.24)$ \\
\hline Education & $(n=6464)$ & $(n=5353)$ & $(n=9531)$ & $(n=6327)$ \\
\hline Degree & 1.00 & 1.00 & 1.00 & 1.00 \\
\hline A-level & $1.16(0.92,1.46)$ & $1.48(1.28,2.15)$ & $1.12(0.92,1.36)$ & $1.17(0.97,1.42)$ \\
\hline O-level & $1.33(1.01,1.74)$ & $1.27(0.90,1.78)$ & $1.07(0.84,1.36)$ & $1.27(0.98,1.65)$ \\
\hline No qualification & $1.59(1.27,1.99)$ & $1.66(1.28,2.15)$ & $1.38(1.14,1.67)$ & $1.42(1.16,1.73)$ \\
\hline Housing tenure & $(n=5727)$ & $(n=4706)$ & $(n=5734)$ & $(n=4712)$ \\
\hline Owner & 1.00 & 1.00 & 1.00 & 1.00 \\
\hline Renting, private & $1.49(1.02,2.17)$ & $1.85(1.20,2.85)$ & $1.41(1.00,1.99)$ & $1.43(0.97,2.11)$ \\
\hline Renting, public & $1.49(1.15,1.92)$ & $1.70(1.22,2.35)$ & $1.66(1.32,2.08)$ & $1.69(1.27,2.24)$ \\
\hline
\end{tabular}

Sex-specific odds ratios (95\% confidence intervals) obtained by multivariable logistic regression analysis adjusting for age, marital status and smoking status. General obesity (BMI $\geq 30 \mathrm{~kg} / \mathrm{m}^{2}$ ); Central obesity (women: waist circumference, $W C \geq 88 \mathrm{~cm}$; men: WC $\geq 102 \mathrm{~cm}$ ). 
Table 2 Odds ratios of general obesity across levels of financial hardship in women and men ( $\geq 50$ years) in the EPIC-Norfolk cohort

\begin{tabular}{|c|c|c|c|c|}
\hline & \multicolumn{4}{|c|}{ Women } \\
\hline & Model A & Model B: $A+$ education & Model C: $B+$ social class & Model D: $C+$ housing tenure \\
\hline \multicolumn{5}{|c|}{ Enough money for needs } \\
\hline More than enough & 1.00 & 1.00 & 1.00 & 1.00 \\
\hline Just enough & $1.50(1.24,1.81)$ & $1.39(1.15,1.69)$ & $1.36(1.12,1.65)$ & $1.34(1.10,1.64)$ \\
\hline Less than enough & $2.56(1.98,3.33)$ & $2.32(1.78,3.03)$ & $2.20(1.68,2.88)$ & $2.04(1.54,2.69)$ \\
\hline \multicolumn{5}{|c|}{ Frequency of not enough money } \\
\hline Never & 1.00 & 1.00 & 1.00 & 1.00 \\
\hline Seldom & $1.41(1.21,1.66)$ & $1.38(1.18,1.62)$ & $1.36(1.16,1.60)$ & $1.35(1.14,1.59)$ \\
\hline Sometimes & $1.64(1.36,1.98)$ & $1.57(1.30,1.90)$ & $1.53(1.26,1.85)$ & $1.44(1.18,1.76)$ \\
\hline Often/Always & $1.68(1.26,2.25)$ & $1.57(1.18,2.10)$ & $1.54(1.15,2.06)$ & $1.40(1.03,1.90)$ \\
\hline \multicolumn{5}{|c|}{ Difficulty paying bills } \\
\hline None & 1.00 & 1.00 & 1.00 & 1.00 \\
\hline Very little & $1.38(1.18,1.62)$ & $1.37(1.16,1.60)$ & $1.33(1.13,1.56)$ & $1.32(1.12,1.56)$ \\
\hline Slight & $1.78(1.41,2.25)$ & $1.75(1.39,2.21)$ & $1.76(1.39,2.23)$ & $1.67(1.32,2.13)$ \\
\hline Some & $2.08(1.66,2.61)$ & $1.99(1.59,2.50)$ & $1.92(1.53,2.42)$ & $1.81(1.43,2.30)$ \\
\hline \multirow[t]{3}{*}{ Great/Nery great } & $2.52(1.60,3.98)$ & $2.37(1.50,3.75)$ & $2.38(1.50,3.78)$ & $2.20(1.37,3.55)$ \\
\hline & \multicolumn{4}{|c|}{ Men } \\
\hline & Model A & Model B: $A+$ education & Model C: B + social class & Model $D: C+$ housing tenure \\
\hline \multicolumn{5}{|c|}{ Enough money for needs } \\
\hline More than enough & 1.00 & 1.00 & 1.00 & 1.00 \\
\hline Just enough & $1.28(1.02,1.59)$ & $1.22(0.97,1.53)$ & $1.18(0.94,1.48)$ & $1.17(0.93,1.47)$ \\
\hline Less than enough & $2.13(1.59,2.85)$ & $2.00(1.49,2.69)$ & $1.93(1.43,2.61)$ & $1.83(1.34,2.49)$ \\
\hline \multicolumn{5}{|c|}{ Frequency of not enough money } \\
\hline Never & 1.00 & 1.00 & 1.00 & 1.00 \\
\hline Seldom & $1.32(1.09,1.60)$ & $1.30(1.07,1.57)$ & $1.29(1.06,1.56)$ & $1.30(1.07,1.59)$ \\
\hline Sometimes & $1.30(1.01,1.66)$ & $1.26(0.98,1.62)$ & $1.24(0.97,1.60)$ & $1.15(0.88,1.49)$ \\
\hline Often/Always & $2.04(1.47,2.84)$ & $1.98(1.42,2.76)$ & $1.93(1.38,2.71)$ & $1.81(1.28,2.56)$ \\
\hline \multicolumn{5}{|c|}{ Difficulty paying bills } \\
\hline None & 1.00 & 1.00 & 1.00 & 1.00 \\
\hline Very little & $1.05(0.87,1.28)$ & $1.04(0.86,1.27)$ & $1.04(0.85,1.26)$ & $1.02(0.84,1.24)$ \\
\hline Slight & $1.18(0.87,1.60)$ & $1.17(0.86,1.59)$ & $1.17(0.86,1.58)$ & $1.13(0.83,1.55)$ \\
\hline Some & $1.61(1.21,2.15)$ & $1.58(1.18,2.11)$ & $1.54(1.15,2.06)$ & $1.39(1.02,1.88)$ \\
\hline Great/Nery great & $2.48(1.45,4.26)$ & $2.43(1.42,4.18)$ & $2.51(1.46,4.34)$ & $2.40(1.38,4.17)$ \\
\hline
\end{tabular}

Sex-specific odds ratios (95\% confidence intervals) for general obesity $\left(\mathrm{BMI} \geq 30 \mathrm{~kg} / \mathrm{m}^{2}\right.$ ) obtained by multivariable logistic regression analysis adjusting for age, marital status and smoking status. Final numbers (Model D) of women and men, respectively, for money $(n=5526 ; n=4588$ ); frequency of not enough money $(n=5536 ; n=4591)$; difficulty paying bills $(n=5542 ; n=4596)$.

associations with obesity for three types of financial hardship that were independent of social class, education and housing tenure. Independent associations were particularly strong for central obesity in women compared to men.

\section{Methodological considerations}

The financial hardship variables were self-reported and like all such variables may be subject to recall or social desirability bias. Interpretation of the meaning of financial hardship can also vary widely across the population; equivalent levels of financial strain can be perceived and experienced as a normative status of daily living for some groups but as deprivation for others [19]. Precedent exists, however, for the measures used here as findings of independent associations are consistent with other studies of self-reported and objective health outcomes in similarly-aged groups $[14,19,20]$. Although financial 
Table 3 Odds ratios of central obesity across levels of financial hardship in women and men ( $\geq 50$ years) in the EPIC-Norfolk cohort

\begin{tabular}{|c|c|c|c|c|}
\hline & \multicolumn{4}{|c|}{ Women } \\
\hline & Model A & Model B: $A+$ education & Model C: $B+$ social class & Model D: $C+$ housing tenure \\
\hline \multicolumn{5}{|c|}{ Enough money for needs } \\
\hline More than enough & 1.00 & 1.00 & 1.00 & 1.00 \\
\hline Just enough & $1.55(1.31,1.83)$ & $1.48(1.25,1.75)$ & $1.50(1.26,1.78)$ & $1.50(1.26,1.78)$ \\
\hline Less than enough & $2.51(1.99,3.18)$ & $2.37(1.86,3.00)$ & $2.32(1.82,2.97)$ & $2.16(1.68,2.78)$ \\
\hline \multicolumn{5}{|c|}{ Frequency of not enough money } \\
\hline Never & 1.00 & 1.00 & 1.00 & 1.00 \\
\hline Seldom & $1.33(1.15,1.53)$ & $1.30(1.13,1.50)$ & $1.29(1.12,1.49)$ & $1.29(1.11,1.49)$ \\
\hline Sometimes & $1.49(1.26,1.77)$ & $1.45(1.22,1.72)$ & $1.44(1.21,1.71)$ & $1.38(1.15,1.65)$ \\
\hline Often/Always & $1.76(1.36,2.29)$ & $1.69(1.30,2.19)$ & $1.65(1.26,2.15)$ & $1.51(1.15,1.99)$ \\
\hline \multicolumn{5}{|c|}{ Difficulty paying bills } \\
\hline None & 1.00 & 1.00 & 1.00 & 1.00 \\
\hline Very little & $1.39(1.21,1.60)$ & $1.38(1.20,1.59)$ & $1.36(1.18,1.56)$ & $1.36(1.17,1.57)$ \\
\hline Slight & $1.57(1.26,1.94)$ & $1.55(1.25,1.92)$ & $1.57(1.26,1.95)$ & $1.50(1.20,1.87)$ \\
\hline Some & $1.74(1.41,2.15)$ & $1.69(1.37,2.09)$ & $1.68(1.36,2.08)$ & $1.59(1.28,1.99)$ \\
\hline \multirow[t]{3}{*}{ Great/Nery great } & $2.66(1.73,4.08)$ & $2.55(1.66,3.92)$ & $2.46(1.59,3.82)$ & $2.34(1.49,3.67)$ \\
\hline & \multicolumn{4}{|c|}{ Men } \\
\hline & Model A & Model B: $A+$ education & Model C: B + social class & Model $D: C+$ housing tenure \\
\hline \multicolumn{5}{|c|}{ Enough money for needs } \\
\hline More than enough & 1.00 & 1.00 & 1.00 & 1.00 \\
\hline Just enough & $1.19(1.00,1.42)$ & $1.14(0.96,1.36)$ & $1.16(0.97,1.39)$ & $1.14(0.95,1.37)$ \\
\hline Less than enough & $1.76(1.38,2.25)$ & $1.66(1.30,2.13)$ & $1.69(1.31,2.17)$ & $1.64(1.26,2.12)$ \\
\hline \multicolumn{5}{|c|}{ Frequency of not enough money } \\
\hline Never & 1.00 & 1.00 & 1.00 & 1.00 \\
\hline Seldom & $1.32(1.13,1.55)$ & $1.30(1.11,1.52)$ & $1.30(1.11,1.53)$ & $1.30(1.11,1.53)$ \\
\hline Sometimes & $1.33(1.08,1.63)$ & $1.29(1.05,1.58)$ & $1.30(1.06,1.60)$ & $1.26(1.01,1.56)$ \\
\hline Often/Always & $1.62(1.20,2.19)$ & $1.58(1.17,2.13)$ & $1.57(1.16,2.13)$ & $1.51(1.11,2.07)$ \\
\hline \multicolumn{5}{|c|}{ Difficulty paying bills } \\
\hline None & 1.00 & 1.00 & 1.00 & 1.00 \\
\hline Very little & $1.14(0.98,1.33)$ & $1.13(0.97,1.32)$ & $1.14(0.98,1.34)$ & $1.13(0.96,1.32)$ \\
\hline Slight & $1.25(0.97,1.61)$ & $1.24(0.97,1.60)$ & $1.25(0.97,1.61)$ & $1.24(0.96,1.61)$ \\
\hline Some & $1.53(1.19,1.96)$ & $1.50(1.17,1.93)$ & $1.47(1.14,1.90)$ & $1.35(1.04,1.77)$ \\
\hline Great/Nery great & $1.48(0.88,2.49)$ & $1.45(0.86,2.44)$ & $1.53(0.90,2.59)$ & $1.49(0.87,2.54)$ \\
\hline
\end{tabular}

Sex-specific odds ratios (95\% confidence intervals) obtained by multivariable logistic regression analysis adjusting for age, marital status and smoking status. Central obesity for women (waist circumference, WC $\geq 88 \mathrm{~cm}$ ) and for men (WC $\geq 102 \mathrm{~cm}$ ). Final numbers (Model D) of women and men, respectively, for money $(n=5533 ; n=4594)$; frequency of not enough money $(n=5543 ; n=4597) ;$ difficulty paying bills $(n=5549 ; n=4602)$.

hardship was assessed before anthropometry measurement, we could not ascertain the duration of, or transition in, hardship in relation to obesity as the survey was administered once. Thus, there may have been misclassification of exposures stemming from changes to participants' hardship levels in the interval between assessment of financial circumstances and anthropometric measurement. Such misclassification would be non-differential since it was unlikely to have been related to our outcomes and hence would have biased results towards the null.

Our findings may also be subject to residual confounding in two ways. First, income was not collected in EPICNorfolk and thus we could not account for income-based differences. However, income is not consistently shown to have an impact on weight in older adults or for both sexes [36,37], and may not sufficiently reflect structural resources in our sample of older adults since they likely 
also use savings to fund their expenses [38]. Our study nevertheless examined six socioeconomic indicators separately and also included education, social class and housing tenure in analyses of financial hardship. Second, parity was not analysed but may have confounded or mediated our associations between socioeconomic factors and obesity $[39,40]$.

Notwithstanding some limitations, the study's strengths include a large sample size, sex-specific analyses, adjustment for multiple known confounders and lifestyle variables, and two objective obesity measures. Finally, this cohort had similar characteristics to the general UK population apart from fewer smokers and lack of ethnic diversity $[23,28]$, and so findings could be generalised to other white European-origin older adults.

\section{Relationship to previous work}

Our work is novel in at least three ways. First, we examined three separate financial hardship exposure measures and thus provide unique information on how different types of the financial hardship domain might be associated with higher prevalence of obesity [41]. We therefore add depth to previous studies which combined hardship questions into one summary indicator $[8,10,14,15,42-45]$. Second, our focus on over-50s contributes new knowledge in support of a healthy ageing agenda as no studies of economic strain and health in older populations have assessed obesity, to our knowledge [19,22]. Third and most notably, our study is clinically relevant. We used two objective measures of obesity recommended as separate predictors of health risk, particularly central adiposity [46], rather than self-reported weight which is prone to systematic bias from inaccuracy of height and underreporting and misclassification for obese categories $[47,48]$.

Our finding that financial hardship showed independent associations with BMI is consistent with current evidence which notably comes from occupational cohorts $[8,14,44]$. The Helsinki Health Study of middle-aged employees, mostly women, reported increased odds of self-reported BMI for frequent financial hardship independent of conventional SES and early life factors [8], but our estimates were slightly larger. Unlike our work, that study of self-reported BMI included only age and no other BMI-related covariates associated with standard SES and obesity [49]. Another study of the same occupational cohort found a higher odds of weight gain $(\geq 5 \mathrm{~kg})$ with increasing frequency of economic difficulties after conventional SES adjustment, but again without accounting for smoking status, living arrangement or other health behaviours [10]. The Whitehall II study of financial hardship and coronary events in middle-aged men also found that a higher economic difficulties score was associated with a higher BMI and waist-hip ratio measured objectively, but the age-adjusted association did not account for conventional SES [14]. To our knowledge, no other studies of financial hardship have reported on central obesity for us to compare our findings.

Existing evidence supports the notion that social inequalities in obesity differ between the sexes with SES differences being associated more strongly and consistently with BMI in women [5-7,50]. Sex differences have also been reported among the few studies examining financial hardship and obesity, suggesting independent associations are stronger in men $[8,10]$. Notably, those results were reported in a younger population comprised of civil servants. The present study of a population-based sample of older British adults revealed contrasting results. Conventional SES proxies appeared to be more strongly and consistently associated with men's higher odds of obesity which does not have a clear explanation. By contrast, the main associations between financial hardship and obesity were larger than SES and stronger in women. However, after adjusting for conventional SES, sex differences observed in the magnitude of associations depended on the type of hardship and obesity measure. This observed reversal between the sexes in the strength of socioeconomic disparities in obesity might point to gender-based differences in the experience of financial hardship. For example, men and women have differential vulnerabilities to financial hardship as women report not having enough money for food twice more often than men [51,52], and they also have differential power in intra-household economics and division of labour [53,54].

Several potential mediators might explain our finding of a link between financial hardship and obesity. Financial hardship is a powerful stressor and sociologists have shown the utility of coping and social support in explaining differences between socially and economically demarcated groups in effects of financial hardship $[42,55]$. Coping behaviours, involving the manipulation of goals and values, were found to be effective for minimizing adverse effects of household financial strain, and to be used to a greater extent by socially advantaged groups, namely men, the educated, and the affluent [55]. Other potential mediators include psychological resources such as self-esteem and sense of mastery [22]. Structural factors range from consumer prices of goods and services (e.g. food, transportation) [43], and neighbourhood access to healthy foods and safe spaces for physical activity [56], to employment $[57,58]$ and cultural norms and social meanings reinforced through media and advertising $[59,60]$. Since financial hardship was a stronger correlate of obesity than conventional SES, excess weight and abdominal fat may be more directly influenced by mechanisms related to spending power and material resources, including lack of sleep from financial worries and physiological responses to hardship-related stress, than by non-material factors such as social roles, cultural norms, 
and knowledge. Both chronic stress and insufficient sleep have independent associations with obesity [61-63].

Although people of all ages may encounter financial hardship, adults in older age groups are at greater risk of increased financial hardship which commonly results from events they are more likely to experience such as divorce, death of spouse, or involuntary job loss [22,42]. Our results suggest that monetary and coping interventions may be useful in efforts to reduce obesity among over-50s. Formal mediation analyses of stress-related indicators are warranted to examine physiological mechanisms of influence between financial hardship and obesity in older women and men. Future research should also explore how both social and economic aspects of an individual's life circumstances interact to produce combined effects on obesity as called for in the public health research and policy literature $[64,65]$. Nevertheless, prevention of obesity in over-50s would benefit more from an increased focus on their experience of financial hardship in addition to their education or income levels.

\section{Conclusions}

British over-50s reporting greater levels of financial hardship were more likely to have excess weight and abdominal fat. Likelihood of obesity was more strongly correlated with financial hardship than conventional markers of SES. Thus, financial hardship indicators provided additional explanatory power beyond education, social class or home-ownership in understanding variation in prevalence of obesity in over-50 women and men. Our findings confirm that it is not sufficient to solely consider education, social class or home-ownership when examining the role of socioeconomic factors in the prevention of obesity or in weight support among older adults. Rather, public health policies and strategies need to support older people in terms of their more contemporaneous economic concerns. Interventions and practice standards to reduce or prevent obesity might include coping and monetary strategies and a focus on meeting bill payments might be a suitable target for approaches to address obesity.

\section{Additional file}

Additional file 1: Figure S1. The process of sample selection from the EPIC-Norfolk cohort. Table S2: Characteristics of self-reported financial hardship for over-50s in the EPIC-Norfolk cohort. Table S3: Odds ratios of general and central obesity in women and men ( $\geq 50$ years) across levels of social class, education, and housing tenure in the EPIC-Norfolk cohort. Table S4: Odds ratio of general obesity across levels of financial hardship in women and men ( $\geq 50$ years) in the EPIC-Norfolk cohort. Table S5: Odds ratio of central obesity across levels of financial hardship in women and men ( $\geq 50$ years) in the EPIC-Norfolk cohort.

\section{Competing interests}

The authors declare that they have no competing interests.

\section{Authors' contributions}

AIC conceived the study, analysed the data, interpreted results and led writing of the manuscript. PM contributed to the study design, supervised the analysis, assisted in interpretation and contributed to the manuscript. NGF and MS informed the study design and analysis. PS designed and implemented the HLEQ Research Programme in the EPIC cohort; NJW is PI on the EPIC Norfolk study. All authors were involved in writing the paper and approved the final version.

\section{Acknowledgements}

The authors thank the EPIC-Norfolk participants and staff for their contributions. AIC acknowledges PhD funding from the Gates Cambridge Trust. The work was undertaken by the Centre for Diet and Activity Research (CEDAR), a UKCRC Public Health Research Centre of Excellence. Funding from the British Heart Foundation, Economic and Social Research Council, Medical Research Council, the National Institute for Health Research, and the Wellcome Trust, under the auspices of the UK Clinical Research Collaboration, is gratefully acknowledged. EPIC-Norfolk is supported by programme grants from the Medical Research Council and Cancer Research UK. We also acknowledge support from the MRC Epidemiology Unit MC_UU_12015/1 and MC_UU_12015/5.

\section{Author details}

${ }^{1}$ MRC Epidemiology Unit, Institute of Metabolic Science, Addenbrooke's Hospital, University of Cambridge, Hills Road, Box 285, Cambridge CB2 0QQ, UK. ${ }^{2}$ UK Clinical Research Collaboration Centre for Diet and Activity Research (CEDAR), Institute of Public Health, Forvie Site, Robinson Way, Box 296, Cambridge CB2 OSR, UK. ${ }^{3}$ Faculty of Medicine and Health Sciences, University of East Anglia, Norwich NR4 7TJ, UK. ${ }^{4}$ Department of Public Health and Primary Care, Institute of Public Health, University of Cambridge, Cambridge CB1 8RN, UK.

Received: 7 August 2013 Accepted: 24 October 2013

Published: 4 November 2013

\section{References}

1. WHO: Global health risks: mortality and burden of disease attributable to selected major risks. Geneva: World Health Organization; 2009.

2. Finkelstein EA, Trogdon JG, Brown DS, Allaire BT, Dellea PS, Kamal-Bahl SJ: The lifetime medical cost burden of overweight and obesity: implications for obesity prevention. Obesity 2008, 16(8):1843-1848.

3. Nolte E, McKee M: Caring for people with chronic conditions: a health system perspective. Maidenhead, UK: Open University Press/McGraw Hill Education; 2008.

4. Wakabayashi I: Necessity of both waist circumference and waist-to-height ratio for better evaluaion of central obesity. Metab Syndr Relat Disord 2013, 11(3):189-94.

5. Pomerlau J, Knai C, Branca F, Robertson A, Rutter H, McKee M, Brunner E, Consortium TE-P: Tackling the social and economic determinants of nutrition and physical activity for the prevention of obesity across Europe: D3.1 Review of the literature of obesity (and inequalities in obesity) in Europe and of its main determinatns: nutrition and physical activity. London, UK: London School of Hygiene\& Tropical Medicine; 2008:1-55.

6. McLaren L: Socioeconomic status and obesity. Epid Rev 2007, 29(1):29-48.

7. Langenberg C, Hardy R, Kuh D, Brunner E, Wadsworth M: Central and total obesity in middle aged men and women in relation to lifetime socioeconomic status: evidence from a national birth cohort. J Epidemiol Commun H 2003, 57(10):816-822.

8. Laaksonen M, Sarlio-Lähteenkorva S, Lahelma E: Multiple dimensions of socioeconomic position and obesity among employees: The Helsinki Health Study. Obes Res 2004, 12(11):1851-1858.

9. Sutton R: Chapter 10: Adult anthropometric measures, overweight and obesit. In Healthy Survey for England - 2011, Health, social care and lifestyles. edn; 2012. [online] http://www.hscic.gov.uk/catalogue/PUB09300: Health \& Social Care Information Centre.

10. Loman T, Lallukka T, Laaksonen M, Rahkonen O, Lahelma E: Multiple socioeconomic determinants of weight gain: the Helsinki Health Study. BMC Public Health 2013, 13:259-266.

11. Ouellette T, Burstein N, Long D, Beecroft E: Measures of material hardship: final report. Washington: U.S. Department of Health and Human Services; 2004. 
12. Laaksonen E, Lallukka T, Lahelma E, Ferrie JE, Rahkonen O, Head J, Marmot MG, Martikainen P: Economic difficulties and physical functioning in Finnish and British employees: contribution of social and behavioural factors. Eur J Public Health 2011, 21(4):456-462.

13. Laaksonen E, Martikainen P, Lallukka T, Lahelma E, Ferrie J, Rahkonen O, Marmot M, Head J: Economic difficulties and common mental disorders among Finnish and British white-collar employees: the contribution of social and behavioural factors. J Epidemiol Commun H 2009, 63(6):439-446.

14. Ferrie J, Martikainen P, Shipley M, Marmot M: Self-reported economic difficulties and coronary events in men: evidence from the Whitehall II study. Int J Epidemiol 2005, 34(3):640-648.

15. Lallukka T, Ferrie JE, Rahkonen $\mathrm{O}$, Shipley MJ, Pietiläinen $\mathrm{O}$, Kivimäki M, Marmot MG, Lahelma E, et al: Change in economic difficulties and physical and mental functioning: evidence from British and Finnish employee cohorts. Scand J Work Environ Health 2013. doi: 10.5271/sjweh.3366.

16. Rahkonen $\mathrm{O}$, Laaksonen M, Karvonen S: The contribution of lone parenthood and economic difficulties to smoking. Soc Sci Med 2005, 61(1):211-216.

17. Averett SL, Smith JK: Financial hardship and obesity: the link between weight and household debt. Women 2013, 100(100):100.

18. Braveman P, Cubbin C, Egerter S, Chideya S, Marchi K, Metzler M, Posner S: Socioeconomic status in health research: one size does not fit all. JAMA 2005, 294(22):2879-2888.

19. Kahn JR, Pearlin LI: Financial strain over the life course and health among older adults. J Health Soc Behav 2006, 47(1):17-31.

20. Lallukka T, Ferrie JE, Kivimäki M, Shipley MJ, Rahkonen O, Lahelma E: Economic difficulties and subsequent sleep problems: evidence from British and Finnish occupational cohorts. Sleep Med 2012, 13(6):680-685.

21. Office of National Statistics: Family spending 2011 edition: a report on the living costs and food survey 2010. London: The Stationery Office; 2011.

22. Pudrovska T, Schieman S, Pearlin LI, Nguyen K: The sense of mastery as a mediator and moderator in the association between economic hardship and health in late life. J Aging Health 2005, 17(5):634-660.

23. Day N, Oakes S, Luben R, Khaw KT, Bingham S, Welch A, Wareham N: EPIC Norfolk: study design and characteristics of the cohort. European Prospective Investigation of Cancer. Br J Cancer 1999, 80(1):95-103.

24. Surtees PG, Wainwright NWJ: The shackles of misfortune: social adversity assessment and representation in a chronic-disease epidemiological setting. Soc Sci Med 2007, 64(1):95-111.

25. Surtees PG, Wainwright NWJ, Brayne C: Psychosocial aetiology of chronic disease: a pragmatic approach to the assessment of lifetime affective morbidity in an EPIC component study. J Epidemio/ Community Health 2000, 54(2):114-122

26. McFadden E, Luben R, Wareham N, Bingham S, Khaw K-T: Occupational social class, risk factors and cardiovascular disease incidence in men and women: a prospective study in the European Prospective Investigation of Cancer and Nutrition in Norfolk (EPIC-Norfolk) cohort. Eur J Epidemiol 2008, 23(7):449-458.

27. Pollack CE, Chideya S, Cubbin C, Williams B, Dekker M, Braveman P: Should health studies measure wealth?: a systematic review. Am J Prev Med 2007 33(3):250-264

28. Surtees PG, Wainwright NWJ, Khaw KT: Obesity, confidant support and functional health: cross-sectional evidence from the EPIC-Norfolk cohort. Int J Obes Relat Metab Disord 2004, 28(6):748-758.

29. Diana Fl, Su H, Winters PC, Liang H: Association of workplace chronic and acute stressors with employee weight status: data from worksites in turmoil. J Occup Environ Med 2010, 52(Suppl 1):S34.

30. Kouvonen A, Stafford M, De Vogli R, Shipley MJ, Marmot MG, Cox T, Vahtera J, Väänänen A, Heponiemi T, Singh-Manoux A, et al: Negative aspects of close relationships as a predictor of increased body mass index and waist circumference: the Whitehall II study. Am J Public Health 2011, 101(8):1474-1480.

31. Brunner EJ, Chandola T, Marmot MG: Prospective effect of job strain on general and central obesity in the Whitehall II study. Am J Epidemiol 2007, 165(7):828-837.

32. Kahn HS, Williamson DF, Stevens JA: Race and weight change in US women: the roles of socioeconomic and marital status. Am J Public Health 1991, 81:319-323.

33. Bingham SA, Gill C, Welch A, Day K, Cassidy A, Khaw K-T, Sneyd M, Key TJA, Roe L, Day NE: Comparison of dietary assessment methods in nutritional epidemiology: weighed records v. $24 \mathrm{~h}$ recalls, food-frequency questionnaires and estimated-diet records. Brit J Nutr 1994, 72(04):619-643.
34. Wareham NJ, Jakes RW, Rennie KL, Mitchell J, Hennings S, Day NE: Validity and repeatability of the EPIC-Norfolk physical activity questionnaire. Int J Epidemiol 2002, 31(1):168-174.

35. StataCorp: Stata Statistical Software: Release 12. College Station, TX StataCorp LP; 2011

36. Cawley J, Moran J, Simon K: The impact of income on the weight of elderly Americans. Health Econ 2010, 19(8):979-993.

37. Yoon YS, Oh SW, Park HS: Socioeconomic status in relation to obesity and abdominal obesity in korean adults: a focus on Sex differences. Obesity 2006, 14(5):909-919.

38. Irz X, Fratiglioni L, Kuosmanen N, Mazzocchi M, Modugno L, Nocella G, Shakersain B, Traill WB, Xu W, Zanello G: Sociodemographic determinants of diet quality of the EU elderly: a comparative analysis in four countries. Public Health Nutr 2013:1-13 [Epub ahead of print].

39. Gunderson EP: Childbearing and obesity in women: weight before, during, and after pregnancy. Obstet Gynecol Clin North Am 2009, 36(2):317.

40. Weng HH, Bastian LA, Taylor DH Jr, Moser BK, Ostbye T: Number of children associated with obesity in middle-aged women and men: results from the Health and Retirement Study. J Womens Health 2004, 13(1):85-91.

41. Turrell G, Hewitt B, Patterson C, Oldenburg B: Measuring socio-economic position in dietary research: is choice of socio-economic indicator important? Public Health Nutr 2003, 6(02):191-200.

42. Pearlin LI: The sociological study of stress. J Health Soc Behav 1989 30(September):241-256.

43. Burns C, Bentley $R$, Thornton L, Kavanagh A: Reduced food access due to a lack of money, inability to lift and lack of access to a car for food shopping: a multilevel study in Melbourne Victoria. Public Health Nutr 2011, 14(06):1017-1023.

44. Lallukka T, Laaksonen M, Rahkonen O, Roos E, Lahelma E: Multiple socioeconomic circumstances and healthy food habits. Eur J Clin Nutr 2006, 61(6):701-710

45. Lallukka T, Lahelma E, Rahkonen O: Changes in economic difficulties and subsequent sickness absence: a prospective register-linkage study. BMJ Open 2013, 3(1):e002212

46. Burkhauser RV, Cawley J: Beyond BMI: The value of more accurate measures of fatness and obesity in social science research. J Health Econ 2008, 27(2):519-529.

47. Klein S, Allison DB, Heymsfield SB, Kelley DE, Leibel RL, Nonas C, Kahn R: Waist circumference and cardiometabolic risk: a consensus statement from shaping America's health: association for weight management and obesity prevention; NAASO, The Obesity Society; The American Society for Nutrition; and The American Diabetes Association. Am J Clin Nutr 2007, 85(5):1197-1202.

48. Janssen I, Katzmarzyk PT, Ross R: Waist circumference and not body mass index explains obesity-related health risk. Am J Clin Nutr 2004, 79(3):379-384

49. Manios Y, Panagiotakos DB, Pitsavos C, Polychronopoulos E, Stefanadis C: Implication of socio-economic status on the prevalence of overweight and obesity in Greek adults: the ATTICA study. Health Policy 2005, 74(2):224-232.

50. Mackenbach JP, Stirbu I, Roskam A-JR, Schaap MM, Menvielle G, Leinsalu M, Kunst AE: Socioeconomic inequalities in health in 22 European countries. N Engl J Med 2008, 358(23):2468-2481.

51. Denton M, Prus S, Walters V: Gender differences in health: a Canadian study of the psychosocial, structural and behavioural determinants of health. Soc Sci Med 2004, 58(12):2585-2600.

52. Bihan H, Castetbon K, Mejean C, Peneau S, Pelabon L, Jellouli F, Le Clesiau H, Hercberg S: Sociodemographic factors and attitudes toward food affordability and health are associated with fruit and vegetable consumption in a low-income French population. J Nutr 2010, 140(4):823-830.

53. Katz E: The intra-household economics of voice and exit. Fem Econ 1997 3(3):25-46.

54. Brines J: Economic dependency, gender, and the division of labor at home. Am J Sociol 1994, 100(3):652-688.

55. Pearlin LI, Schooler C: The structure of coping. J Health Soc Behav 1978, 19(March):2-21.

56. Kamphuis CBM: Explaining socioeconomic inequalities in health behaviours: the role of environmental factors. Rotterdam: Erasmus; 2008.

57. Rodriguez Martin A, Martinez J, Novalbos Ruiz J, Escobar Jimenez L: Overweight and obesity: the role of education, employment and income in Spanish adults. Appetite 2008, 51(2):266-272. 
58. Rosmond R, Björntorp P: Psychosocial and socio-economic factors in women and their relationship to obesity and regional body fat distribution. Int J Obes 1999, 23(2):138-145.

59. Murcott A: The sociology of food and eating. Aldershot, UK: Gower Publishing Company Ltd.; 1993.

60. Lumbers M, Raats M: Food choices in later life. In The Psychology of Food Choice. Volume Frontiers in Nutritional Science. 3rd edition. Edited by Shepherd R, Raats M. Wallingford, UK: CABI Publishing; 2006:280-310.

61. Bose M, Olivan B, Laferrere B: Stress and obesity: the role of the hypothalamic-pituitary-adrenal axis in metabolic disease. Curr Opin Endocrinol Diabetes Obes 2009, 16(5):340-346.

62. Cappuccio FP, Taggart FM, Kandala N-B, Currie A, Peile E, Stranges S, Miller MA: Meta-analysis of short sleep duration and obesity in children and adults. Sleep 2008, 31(5):619-626.

63. Björntorp P: Do stress reactions cause abdominal obesity and comorbidities? Obes Rev 2001, 2(2):73-86.

64. Killoran A, Kelly M: Evidence based public health: effectiveness and efficiency. Oxford, UK: Oxford University Press; 2010.

65. Kelly M: Social differences in populations and their implications for public health. Perspect Public Health 2009, 129(5):207-208.

doi:10.1186/1471-2458-13-1039

Cite this article as: Conklin et al:: Socioeconomic status, financial

hardship and measured obesity in older adults: a cross-sectional study of the EPIC-Norfolk cohort. BMC Public Health 2013 13:1039.

\section{Submit your next manuscript to BioMed Central and take full advantage of:}

- Convenient online submission

- Thorough peer review

- No space constraints or color figure charges

- Immediate publication on acceptance

- Inclusion in PubMed, CAS, Scopus and Google Scholar

- Research which is freely available for redistribution 